\title{
Anika Mitzkait
}

\section{Leistungsstörung und Haftungsbefreiung}

Ein Vergleich der Grundregeln des Europäischen Vertragsrechts mit dem reformierten deutschen Recht

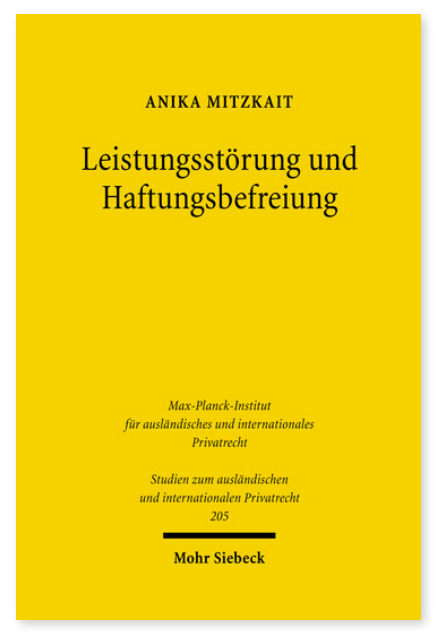

2008. XVI, 293 Seiten. StudIPR 205

ISBN 978-3-16-151390-9

DOI 10.1628/978-3-16-151390-9

eBook PDF $74,00 €$
Die Schuldrechte der Staaten Europas sind zunehmendem Vereinheitlichungsdruck unterworfen. Dies dokumentieren zahlreiche Sekundärrechtsakte der europäischen Gemeinschaft, aber auch die Arbeiten einiger Forschergruppen, die im Auftrag der EU-Kommission daran arbeiten, nach dem Vorbild der US-amerikanischen Restatements of the Law die Gemeinsamkeit der europäischen Rechtsordnungen herauszuschälen und Vereinheitlichungsvorschläge zu unterbreiten. An diesen Vorschlägen hat sich teilweise auch der deutsche Gesetzgeber bei seiner jüngsten Reform des Schuldrechts orientiert eine Reform, die bekanntlich unter großem Zeitdruck erfolgt ist. Anika Mitzkait vergleicht für das allgemeine Leistungsstörungsrecht die beiden modernsten europäischen Regelwerke miteinander: Das reformierte deutsche Recht und die (nicht staatlichen) Principles of European Contract Law (PECL). Der Rechtsvergleich verfolgt dabei nicht nur den Zweck, das Maß der Angleichung des deutschen Rechts an die Standards der PECL zu untersuchen. Es geht der Autorin vielmehr auch in Gestalt wertender Rechtsvergleichung um einen echten Systemwettbewerb, d.h. um Antworten auf die Frage, welches Modell dogmatisch und von seinen Ergebnissen her überzeugender erscheint.

Anika Mitzkait Geboren 1974; Studium der Rechtswissenschaften an der HU Berlin und in Bordeaux; 2000-2005 wiss. Mitarbeiterin an der FU Berlin; Rechtsanwältin bei Freshfields Bruckhaus Deringer in Berlin.

Jetzt bestellen:

https://mohrsiebeck.com/buch/leistungsstoerung-und-haftungsbefreiung-9783161513909?no_cache=1 order@mohrsiebeck.com

Telefon: +49 (0)7071-923-17

Telefax: $+49(0) 7071-51104$ 